\title{
Endothelial progenitor cell impairment mediated vasodilation dysfunction via diminishing nitric oxide production in postmenopausal females
}

\author{
WAN-ZHOU WU ${ }^{1 *}$, DA-JUN HU ${ }^{1,2^{*}}$, ZHEN-YU WANG $^{1}$, LONG-SHENG LIAO $^{1}$ and CHUAN-CHANG LI ${ }^{1}$ \\ ${ }^{1}$ Department of Geriatric Medicine, Xiangya Hospital, Central South University, Changsha, Hunan 410078; \\ ${ }^{2}$ Department of Cardiovascular Medicine, First People's Hospital of Chenzhou, Chenzhou, Hunan 423000, P.R. China
}

Received May 10, 2018; Accepted November 28, 2018

DOI: $10.3892 / \mathrm{mmr} .2019 .9888$

\begin{abstract}
Vascular endothelial dysfunction is the major contributing factor to hypertension. Endothelial progenitor cells (EPCs) are essential for endogenous vascular endothelial renovation. The activity and number of circulating EPCs are preserved in prehypertensive premenopausal females according to our previous research. However, the changes of EPCs in prehypertensive postmenopausal females are poorly understood, and the mechanisms responsible for the loss of the gender protection advantage of cardiovascular disease remain unexplored. In order to determine the effects of EPCs in prehypertensive postmenopausal females, the number and activity of circulating EPCs were tested in the present study. Next, the function of EPCs secreting nitric oxide (NO), vascular endothelial growth factor (VEGF) and granulocyte-macrophage colony-stimulating factor (GM-CSF), as well as their concentration in the plasma, were measured. The association between flow-mediated dilation (FMD) and EPC secretion was also assessed. Attenuation of proliferation and migration of EPCs was observed in prehypertensive patients in comparison with normotensive subjects. In addition, a reduced NO production secreted by EPCs was detected in prehypertensive patients as compared with that in normotensive patients. There was no significant difference in EPC function between postmenopausal females and age-matched males. Finally, the association between FMD and NO production was validated. Collectively, these data indicated that impaired EPCs mediated vasodilation dysfunction via decreasing NO production. Therefore, EPC function enhancement and NO level augmentation are
\end{abstract}

Correspondence to: Dr Chuan-Chang Li, Department of Geriatric Medicine, Xiangya Hospital, Central South University, 87 Xiangya Road, Changsha, Hunan 410078, P.R. China

E-mail: lichuanchang@csu.edu.cn

*Contributed equally

Key words: endothelial progenitor cells, nitric oxide, prehypertension, postmenopausal females emerging as novel therapeutic strategies for prehypertension therapy.

\section{Introduction}

Prehypertension is the intermediate period prior to the pathogenesis of hypertension, as proposed by the seventh report of the Joint National Committee (JNC) in 2003 (1). It is defined as a systolic blood pressure (SBP) between 120 and $139 \mathrm{mmHg}$, and/or a diastolic blood pressure (DBP) between 80 and $89 \mathrm{mmHg}$. Prehypertension represents a high risk of developing hypertension and a number of future clinical outcomes, such as coronary artery disease, myocardial infarction, early arteriosclerosis, chronic kidney disease and heart failure (2-8). Schlaich et al (9) and Taddei et al (10) have demonstrated that endothelial dysfunction is critical in the development of essential hypertension. Similarly, the number of senescent endothelial progenitor cells (EPCs) increased in prehypertensive subjects, while the nitric oxide (NO) production is reduced (11). Bone marrow-derived circulating EPCs are involved in the repair of the vascular endothelium, promotion of neovascularization, restoration of endothelial impairment, and amelioration of vascular endothelial function $(12,13)$. A weakened endothelial repair capability, caused by EPC deactivation, may contribute to prehypertension-associated cardiovascular events $(11,14)$.

A lower morbidity of cardiovascular disease (CVD) is observed in premenopausal females in comparison with that in age-matched males; yet, an increase in the incidence of this disease has been reported following menopause, which indicates that estradiol may be a protective factor against CVD $(15,16)$. Seminal studies have revealed that, in postmenopausal females, the increased incidence of CVD is associated with endothelial dysfunction $(17,18)$. Furthermore, apobiotic circulating EPCs have been detected in prehypertensive patients, which are closely associated with endothelial dysfunction $(11,14)$. In vitro, estrogen-treated EPCs exhibited higher migratory and tube-forming capacities, whereas in vivo studies indicated that estrogen was unable to affect the number of circulating EPCs (19). Our earlier study confirmed that highly active circulating EPCs were maintained in prehypertensive premenopausal females (20). However, the number and activity of circulating EPCs in prehypertensive 
postmenopausal females remain undetermined, and the association between flow-mediated dilation (FMD) and the activity of EPCs has yet to be examined.

Earlier studies have demonstrated that nitric oxide (NO), vascular endothelial growth factor (VEGF) and granulocyte-macrophage colony-stimulating factor (GM-CSF) modulate the number and activity of circulating EPCs (21-24). In our previous study (20), the correlation of highly active circulating EPCs in prehypertensive premenopausal females with NO production was confirmed. Accordingly, the present study aimed to investigate the number and the function of circulating EPCs in subjects with prehypertension and normotension. Additionally, potential sex-associated differences in EPC number and function were examined.

Herein, the levels of NO in the culture medium or plasma, as well as the levels of VEGF and GM-CSF, were determined. Finally, the study explored the association of circulating EPCs with FMD.

\section{Materials and methods}

Study population. A total of 80 subjects were enrolled in the present study, including 20 normotensive postmenopausal females, 20 prehypertensive postmenopausal females, 20 normotensive males and 20 prehypertensive males. The prehypertensive subjects exhibited an SBP between 120 and $139 \mathrm{mmHg}$, and/or a DBP between 80 and $89 \mathrm{mmHg}$, according to the guidelines established by the eighth report of the JNC (25). All normotensive subjects had an SBP of $<120 \mathrm{mmHg}$ and a DBP of $<80 \mathrm{mmHg}$, and presented no cardiovascular risk factors. The subjects recruited into the present study did not suffer from CVD or metabolic disease, as determined by assessment of their entire clinical history and auxiliary examinations. In addition, subject with conditions that may affect the number of EPCs, such as diabetes mellitus, malignant disease, uncontrolled infection and smoking, were excluded. Subjects with previous hysterectomy were also excluded. All subjects were recruited between January 2016 and January 2017, from Xiangya Hospital, Central South University (Changsha, China), and written informed consent was provided for participation. The experimental protocol was approved by The Ethical committee of Xiangya Hospital (ethical license ID of human clinical trial, no. 201503377). The baseline clinical data of the subjects, which were divided into four groups, are listed in Table I.

Clinical measurements. Serum samples were collected in the morning after overnight fasting from the study population ( $\mathrm{n}=80 ; 40$ females and 40 males), and the levels of EPCs, total cholesterol (TC), high-density lipoprotein cholesterol (HDL), low-density lipoprotein cholesterol (LDL), triglycerides (TG) and estradiol were measured. All subjects avoided ingesting alcohol or caffeine for half a day prior to specimen collection. Subjects receiving drug treatments, including antiplatelet agents, anti-inflammatory drugs and hypolipidemic agents, were excluded from the study to reduce potential external effects on the number and activity of circulating EPCs.

EPC isolation, culture and flow cytometric analysis. The number of EPCs in the serum was tested according to previous studies $(20,24,26-28)$. Briefly, Ficoll density gradient centrifugation was used to isolate the peripheral blood mononuclear cells, and then cells were suspended in Endothelial Cell Growth Medium 2 (500 ml; Lonza Group, Ltd., Basel, Switzerland) supplemented with $2 \%$ fetal bovine serum (FBS; Sigma-Aldrich; Merck KGaA, Darmstadt, Germany). Next, the cell suspension $\left(2.5 \times 10^{6} / \mathrm{ml}\right)$ was transferred into $25-\mathrm{cm}^{2}$ cell culture flasks (Corning, Inc., Corning, NY, USA), coated with fibronectin (Clonetics Corporation, San Diego, CA, USA), and incubated at $37^{\circ} \mathrm{C}$ in a humidified atmosphere containing $5 \% \mathrm{CO}_{2}$. After 4 days, nonadherent cells were discarded, while adherent cells were maintained for a further 7 days, and these cells were then utilized in subsequent experiments.

After the 7-day culture, endothelial marker proteins were assessed by flow cytometry. Cell suspension (100 $\mu \mathrm{l})$ was incubated for $40 \mathrm{~min}$ at $4^{\circ} \mathrm{C}$ with the following primary antibodies: Fluorescein isothiocyanate (FITC) anti-human CD45 (1:10; cat. no. FHF045-025; 4A Biotech, Co., Ltd., Beijing, China), phycoerythrin (PE)-Cy7 anti-human CD34 (1:10; cat. no. FHN034-025; 4A Biotech, Co., Ltd.) and PE-conjugated anti-kinase-insert domain receptor (KDR; 1:20; cat. No. FHK309-025; 4A Biotech, Co., Ltd.). Following erythrocyte lysis, the remaining cells were washed with phosphate-buffered saline (PBS) and fixed in 4\% paraformaldehyde for $10 \mathrm{~min}$ at $37^{\circ} \mathrm{C}$. Flow cytometric analysis was conducted with an ACEA NovoCyte ${ }^{\mathrm{TM}}$ flow cytometer (ACEA Biosciences, San Diego, CA, USA), and the results were analyzed with NovoExpress software ${ }^{\mathrm{TM}}$ (ACEA Biosciences). The number of circulating EPCs was determined according to the ratio of $\mathrm{CD} 45{ }^{-} \mathrm{CD} 34^{+} \mathrm{KDR}^{+}$cells per 100 peripheral blood mononuclear cells.

In order to determine the EPC phenotype, mononuclear cells $\left(2.5 \times 10^{6} / \mathrm{ml}\right)$ were plated on cell culture flasks with endothelial cell growth medium (EGM ${ }^{\mathrm{TM}}-2$; Lonza Group, Ltd., Basel, Switzerland). Following 7 days of culturing, the attached endothelial cell-like cells were incubated with DiI-labeled acetylated LDL (Molecular Probes; Thermo Fisher Scientific, Inc.) for $1 \mathrm{~h}$ at $37^{\circ} \mathrm{C}$. Subsequent to fixing in $4 \%$ paraformaldehyde for $30 \mathrm{~min}$ at $37^{\circ} \mathrm{C}$, the cells were incubated with FITC-labeled lectin (Sigma-Aldrich; Merck KGaA) for $4 \mathrm{~h}$ at $37^{\circ} \mathrm{C}$. Following incubation with FITC-labeled lectin, the samples were observed under a phase-contrast fluorescence microscope (magnification, x200). Cells presenting double-positive fluorescence were identified as differentiating EPCs by two independent researchers blinded to the study groups.

EPC migration and proliferation assay. The EPC migration and proliferation assays were conducted as previously described $(20,24,27-29)$. In order to determine the cell proliferation, EPCs were harvested by centrifugation at $438 \mathrm{x} \mathrm{g}$ for $5 \mathrm{~min}$ at $4^{\circ} \mathrm{C}$ and resuspended in $500 \mu \mathrm{l} \mathrm{EGM-2.} \mathrm{A} \mathrm{total}$ of $2 \times 10^{4} \mathrm{EPCs} /$ well were added into the upper chamber of a modified Boyden chamber (24-well Costar Transwell plate; pore size, $8 \mu \mathrm{m}$; Corning, Inc.), while $500 \mu 1$ EGM-2 supplemented with $50 \mathrm{ng} / \mathrm{ml}$ VEGF was added to the lower chamber. Following incubation at $37^{\circ} \mathrm{C}$ for $24 \mathrm{~h}$, the lower side of the filter was washed with PBS and fixed with $2 \%$ paraformaldehyde for $10 \mathrm{~min}$ at $37^{\circ} \mathrm{C}$. Cell nuclei were then stained with DAPI. Cells that had migrated into the lower chamber were 
Table I. Clinical and biochemical characteristics of study participants $(n=80)$.

\begin{tabular}{|c|c|c|c|c|}
\hline Characteristic & $\begin{array}{l}\text { Normotensive } \\
\text { postmenopausal } \\
\text { females }(n=20)\end{array}$ & $\begin{array}{l}\text { Prehypertensive } \\
\text { postmenopausal } \\
\text { females }(n=20)\end{array}$ & $\begin{array}{l}\text { Normotensive } \\
\text { males }(n=20)\end{array}$ & $\begin{array}{l}\text { Prehypertensive } \\
\text { males }(n=20)\end{array}$ \\
\hline Age (years) & $58.8 \pm 2.7$ & $57.5 \pm 2.8$ & $59.2 \pm 3.6$ & $58.5 \pm 3.9$ \\
\hline Height (cm) & $158.9 \pm 5.5$ & $157.9 \pm 5.5$ & $165.8 \pm 5.6^{b}$ & $167.2 \pm 4.7^{b}$ \\
\hline Weight (kg) & $58.5 \pm 3.8$ & $59.0 \pm 5.9$ & $63.0 \pm 5.9^{\mathrm{b}}$ & $66.8 \pm 8.5^{b}$ \\
\hline BMI (kg/cm²) & $23.2 \pm 1.8$ & $23.6 \pm 1.7$ & $22.9 \pm 1.6$ & $23.8 \pm 2.5$ \\
\hline SBP (mmHg) & $108.2 \pm 7.2$ & $132.1 \pm 4.7^{\mathrm{a}}$ & $109.4 \pm 6.1$ & $130.1 \pm 5.5^{\mathrm{a}}$ \\
\hline DBP (mmHg) & $67.4 \pm 4.5$ & $82.1 \pm 4.4^{\mathrm{a}}$ & $68.8 \pm 4.8$ & $80.0 \pm 4.0^{\mathrm{a}}$ \\
\hline HR (beats/min) & $75.7 \pm 8.8$ & $73.5 \pm 6.3$ & $76.7 \pm 8.9$ & $77.2 \pm 7.4$ \\
\hline $\mathrm{AST}(\mathrm{mmol} / \mathrm{l})$ & $21.9 \pm 5.3$ & $22.5 \pm 6.1$ & $23.2 \pm 5.7$ & $24.1 \pm 5.2$ \\
\hline ALT (mmol/l) & $20.6 \pm 5.9$ & $20.8 \pm 4.7$ & $21.2 \pm 6.3$ & $23.6 \pm 5.6$ \\
\hline BUN (mmol/l) & $5.5 \pm 0.7$ & $5.2 \pm 1.0$ & $5.4 \pm 1.0$ & $5.5 \pm 0.7$ \\
\hline $\mathrm{Cr}(\mathrm{mmol} / \mathrm{l})$ & $68.1 \pm 11.5$ & $65.9 \pm 11.9$ & $70.6 \pm 11.5$ & $71.9 \pm 11.8$ \\
\hline LDL (mmol/l) & $2.72 \pm 0.40$ & $2.67 \pm 0.43$ & $2.57 \pm 0.39$ & $2.74 \pm 0.37$ \\
\hline TC (mmol/l) & $4.55 \pm 0.67$ & $4.46 \pm 0.54$ & $4.33 \pm 0.54$ & $4.61 \pm 0.53$ \\
\hline HDL (mmol/l) & $1.48 \pm 0.22$ & $1.50 \pm 0.22$ & $1.52 \pm 0.20$ & $1.45 \pm 0.17$ \\
\hline $\mathrm{TG}(\mathrm{mmol} / \mathrm{l})$ & $1.37 \pm 0.19$ & $1.35 \pm 0.20$ & $1.31 \pm 0.16$ & $1.38 \pm 0.18$ \\
\hline FPG (mmol/l) & $4.73 \pm 0.50$ & $4.60 \pm 0.47$ & $4.45 \pm 0.53$ & $4.63 \pm 0.44$ \\
\hline FMD $(\%)$ & $7.54 \pm 1.77$ & $5.72 \pm 1.28^{\mathrm{a}}$ & $7.49 \pm 1.55^{\mathrm{b}}$ & $5.38 \pm 1.46^{\mathrm{a}, \mathrm{b}}$ \\
\hline
\end{tabular}

${ }^{\mathrm{a}} \mathrm{P}<0.05$ vs. normotensive subjects in the same sex group; ${ }^{\mathrm{b}} \mathrm{P}<0.05$ vs. postmenopausal females in the corresponding normotensive or prehypertensive group. Data are presented as the mean \pm standard deviation. BMI, body mass index; SBP, systolic blood pressure; DBP, diastolic pressure; HR, heart rate; AST, aspartate transaminase; ALT, alanine aminotransferase; BUN, blood urea nitrogen; Cr, creatinine; LDL, low-density lipoprotein; TC, total cholesterol; HDL, high-density lipoprotein; TG, triglyceride; FPG, fasting plasma glucose; FMD, flow-mediated dilation .

manually counted in three random fields under a fluorescence microscope by two independent blinded investigators.

EPC proliferation was determined using an MTT assay. Briefly, EPCs were digested with $0.25 \%$ trypsin and then cultured in serum-free medium in a 96-well culture plate (2,000 cells/well) for $24 \mathrm{~h}$. Next, the EPCs were supplemented with $10 \mu \mathrm{l}$ MTT (5 g/l; Sigma-Aldrich; Merck KGaA, Darmstadt, Germany) and incubated for a further $4 \mathrm{~h}$. The supernatant was then aspirated and discarded. Subsequent to mixing the EPC preparation with $200 \mu 1$ dimethyl sulfoxide by shaking for $10 \mathrm{~min}$, the optical density value at $490 \mathrm{~nm}$ was measured $(20,24,28,29)$.

Detection of plasma NO, VEGF and GM-CSF levels. The Griess method was used to determine the inactive metabolite of NO in the plasma, as reported in earlier studies $(20,24)$, and the results are expressed as $\mu \mathrm{mol} \mathrm{NO}_{\mathrm{x}}$ of $\mathrm{NO}_{3}^{-} / \mathrm{NO}_{2}^{-}$per liter of medium. In addition, in order to measure the levels of VEGF and GM-CSF in the plasma, high-sensitivity enzyme-linked immunosorbent assay (ELISA; R\&D Systems, Inc., Wiesbaden, Germany) was conducted according to the manufacturer's protocol.

Detection of NO, VEGF and GM-CSF secretion by EPCs. EPCs were cultured in Dulbecco's modified Eagle's medium (Gibco; Thermo Fisher Scientific, Inc.) supplemented with $20 \%$ FBS (Sigma-Aldrich; Merck KGaA) for 48 h. Subsequently, in order to measure the levels of NO, VEGF and GM-CSF secretion in the conditioned media of EPCs, the Griess method and ELISA assays were conducted in accordance with the aforementioned protocol.

FMD. The assessment of FMD was performed as described in previous studies $(30,31)$. The brachial artery FMD was assessed by a trained investigator with high-resolution ultrasonography using a 5-12-MHz linear transducer on an HDI 5000 system (Philips Medical Systems, Inc., Bothell, WA, USA). After a 15-min rest, the brachial artery was studied at 20-100 mm proximal to the antecubital fossa in supine position. An upper-forearm sphygmomanometer cuff was inflated to raise the pressure to $250 \mathrm{mmHg}$, and this was maintained for $5 \mathrm{~min}$. The FMD was then calculated as the percentage of increase in the mean diastolic diameter reactive to hyperemia at 55-65 sec after deflation to baseline. After a further $15 \mathrm{~min}$, $400 \mu \mathrm{g}$ sublingual glyceryl trinitrate was administered, and the diastolic diameter was measured again after $5 \mathrm{~min}$ to determine the endothelial independent dilation.

Statistical analysis. All data were analyzed using the SPSS statistical software package, version 11.0 (SPSS, Inc., Chicago, IL, USA), and are presented as the mean \pm standard deviation. Two-way analysis of variance was used to compare between the four groups. When a significant F-value was observed, the Newman-Keuls method was applied as a post hoc test to identify differences among mean values. Univariate correlations were examined by Pearson's correlation coefficient method. 

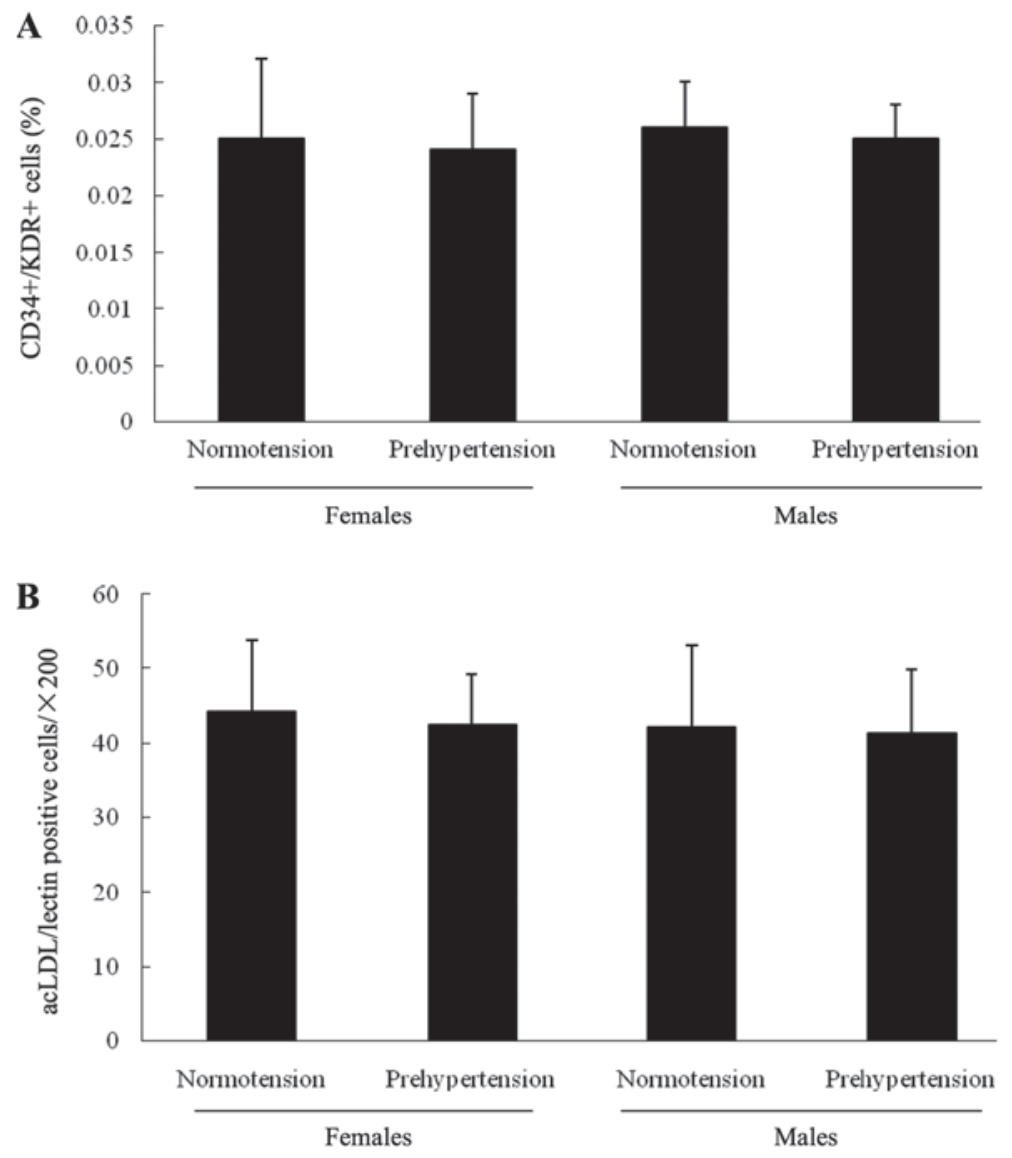

Figure 1. Number of circulating EPCs. EPCs were evaluated based on (A) the number of circulating CD34/KDR double positive cells, as measured by flow citometry, and (B) the number of acLDL/lectin positive cells, measured using a phase-contrast fluorescence microscope (magnification, x200). No significant difference was detected in the number of circulating EPCs among the four groups. Data are presented as the mean \pm standard deviation. EPCs, endothelial progenitor cells. KDR, kinase-insert domain receptor; acLDL, acetylated low-density lipoprotein.

A P-value of $<0.05$ was considered to denote a difference that was statistically significant.

\section{Results}

Clinical baseline characteristics. The essential characteristics of the study population are summarized in Table I. No marked differences were observed with regard to the patient age and body mass index among the subjects. The SBP and DBP values were markedly lower in normotensive males and normotensive postmenopausal females as compared with those in prehypertensive subjects of the same sex, respectively. However, the levels of TC, HDL, LDL, TG and plasma glucose were similar among the four groups. Furthermore, FMD in prehypertensive postmenopausal females was significantly lower in comparison with that in normotensive postmenopausal females. Similarly, FMD was lower in prehypertensive males as compared with that in normotensive males. Additionally, FMD in postmenopausal females was increased compared with male subjects, regardless of the level of blood pressure.

Number andactivity of circulating EPCs. Todetermine whether the circulating EPC was associated with prehypertension, their number and activity was determined. The results shown in Fig. 1 indicated that there was no significant difference in circulating EPCs between normotensive and prehypertensive postmenopausal females, or between normotensive and prehypertensive males. In addition, no notable difference was detected in circulating EPCs between normotensive males and females (postmenopausal), or between prehypertensive males and females (postmenopausal). Furthermore, the number of EPCs determined by the cell culture assay exhibited no significant difference among the four groups.

The migration and proliferation of EPCs were then examined, and the results are shown in Fig. 2. As compared with normotensive postmenopausal females or males, the migration of EPCs was attenuated in the prehypertensive postmenopausal females and males, respectively. Similarly, the proliferation of EPCs in normotensive subjects was significantly higher compared with that of prehypertensive subjects in the same sex group, respectively. However, no marked difference in migration and proliferation of circulating EPCs was observed between normotensive males and females, or between prehypertensive males and females.

Plasma levels of NO, VEGF and GM-CSF. To investigate the mechanism leading to differences in the activity of circulating EPCs, the levels of certain factors present in the plasma influencing the function of EPCs were examined. The levels of NO, VEGF and GM-CSF detected in the plasma of the four groups are displayed in Fig. 3. As shown in Fig. 3A, the plasma NO level in postmenopausal females with prehypertension or 


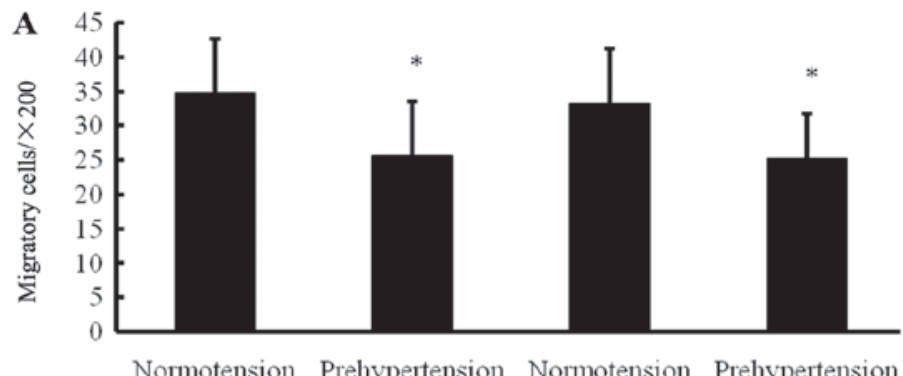

Normotension Prehypertension Normotension Prehypertension

\section{Females}

Males

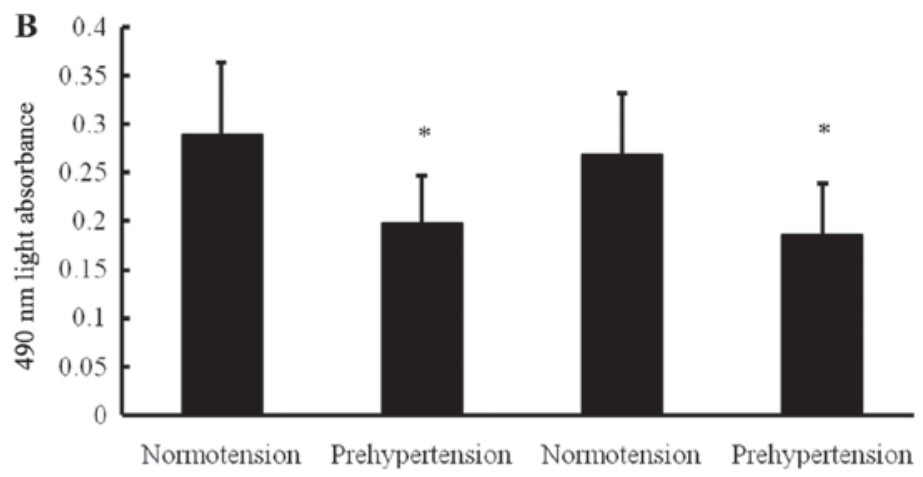

Females

Males

Figure 2. Activity of circulating EPCs. (A) Migratory and (B) proliferative activities of circulating EPCs. The EPC function in prehypertensive males and postmenopausal females was weaker compared with that in normotensive males and females (postmenopausal), respectively. However, the EPC activities were not markedly different between normotensive males and females, and between prehypertensive males and females (postmenopausal), respectively. Data are presented as the mean \pm standard deviation. ${ }^{*} \mathrm{P}<0.05$ vs. normotensive subjects in the same sex group. EPCs, endothelial progenitor cells.
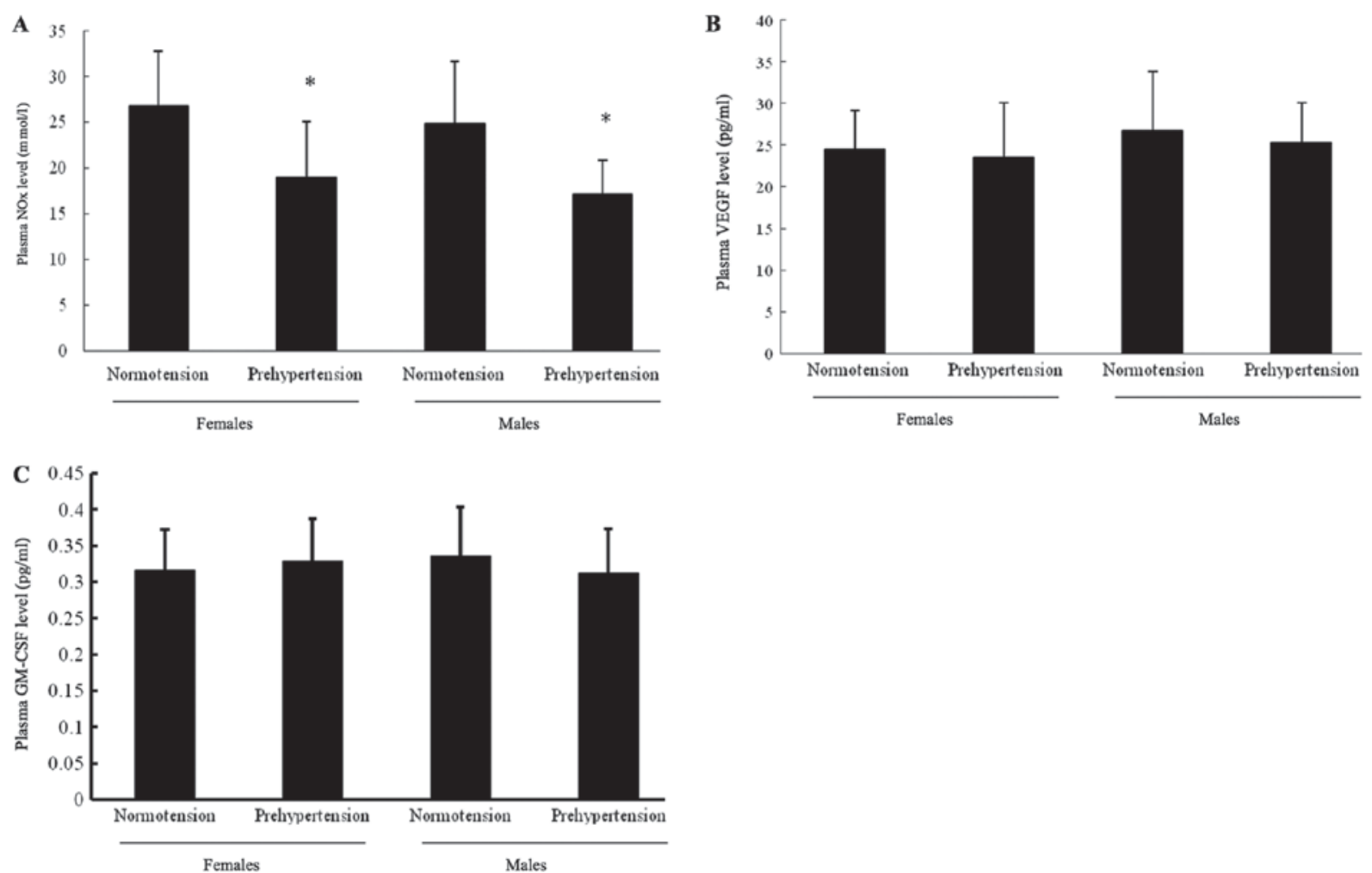

Figure 3. Plasma levels of NO, VEGF and GM-CSF. (A) Plasma NO levels in prehypertensive males and females (postmenopausal) was markedly lower in comparison with that in normotensive males and females (postmenopausal), whereas no difference was detected between the two normotensive or the two prehypertensive groups. (B) VEGF and (C) GM-CSF levels in the plasma did not differ significantly among the four groups. Data are presented as the mean \pm standard deviation. "P<0.05 vs. normotensive subjects in the same sex group. EPCs, endothelial progenitor cells; NO, nitric oxide; VEGF, vascular endothelial growth factor; GM-CSF, granulocyte-macrophage colony-stimulating factor. 

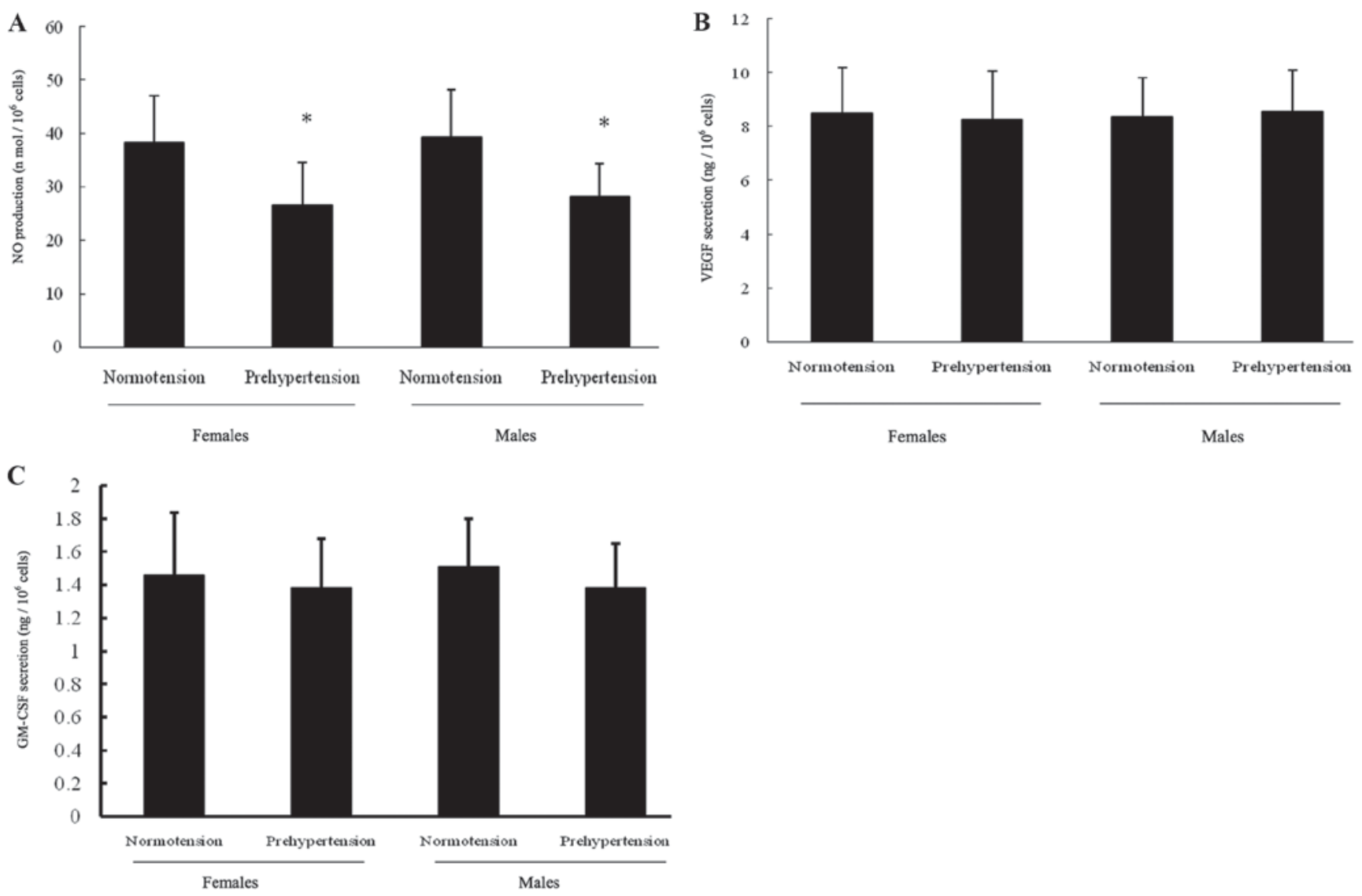

Figure 4. NO, VEGF and GM-CSF secretion by EPCs. (A) NO secretion by EPCs in prehypertensive males and females was significantly lower compared with that in normotensive males and females, respectively. By contrast, no difference was detected in NO secretion by EPCs between the normotensive males and females, or between the prehypertensive males and females. (B) VEGF and (C) GM-CSF secretion by EPCs did not differ significantly among the four groups. Data are given as the mean \pm standard deviation. ${ }^{~} \mathrm{P}<0.05$ vs. normotensive subjects in the same sex group. EPCs, endothelial progenitor cells; $\mathrm{NO}$, nitric oxide; VEGF, vascular endothelial growth factor; GM-CSF, granulocyte-macrophage colony-stimulating factor.

prehypertensive males was significantly lower compared with that in normotensive postmenopausal females or normotensive males, respectively. However, the plasma level of NO presented no notable difference between the two prehypertensive males or postmenopausal females, and between the two normotensive groups. As exhibited in Fig. 3B, the plasma VEGF level did not significantly differ in any of the four groups. Similar to VEGF, the plasma GM-CSF level shown in Fig. 3C exhibited no evident difference among the four groups.

NO, VEGF and GM-CSF secretion by EPCs. As displayed in Fig. 4, the secretion of NO, VEGF and GM-CSF by EPCs among the four groups was consistent with their distribution in the plasma. In brief, NO production in prehypertensive postmenopausal females declined in comparison with that in normotensive postmenopausal females. Similar results were observed when comparing prehypertensive with normotensive males. By contrast, VEGF and GM-CSF secretion by EPCs did not differ among the four groups.

Correlations of circulating EPC function and NO level with $F M D$. The study then sought to explore the correlation of FMD with the NO level or circulating EPCs. As exhibited in Fig. 5A, a strong univariate correlation between FMD and the migratory activity of circulating EPCs was ascertained. Similarly, as shown in Fig. 5B, the FMD enhancement was concordant with
EPC proliferation promotion. As presented in Fig. 5C and D, the FMD significantly increased with the increase in plasma NOx level and the NO production secreted by EPCs.

\section{Discussion}

In the present study, it was demonstrated that the proliferation and the migration of EPCs were decreased in prehypertensive postmenopausal females relative to the normotensive postmenopausal females, although there was no significant change in the number of EPCs. This phenomenon was also observed between normotensive and prehypertensive males. The data also verified that the NO level in the plasma and NO secretion by EPCs declined in both prehypertensive postmenopausal females and age-matched males, as compared with the corresponding normotensive groups. This indicated that circulating NO level and the NO secretion function of EPCs may be connected to pathophysiological processes of prehypertension. In addition, the positive correlation of FMD with both circulating EPC function (migration and proliferation) and NO production was confirmed. These results are concordant with the findings of our previous study (20). The previous study reported that an increased number and activity of EPCs in premenopausal females in comparison with age-matched males. However, in the present study, there was no evidence that the activity and number of EPCs differed between 

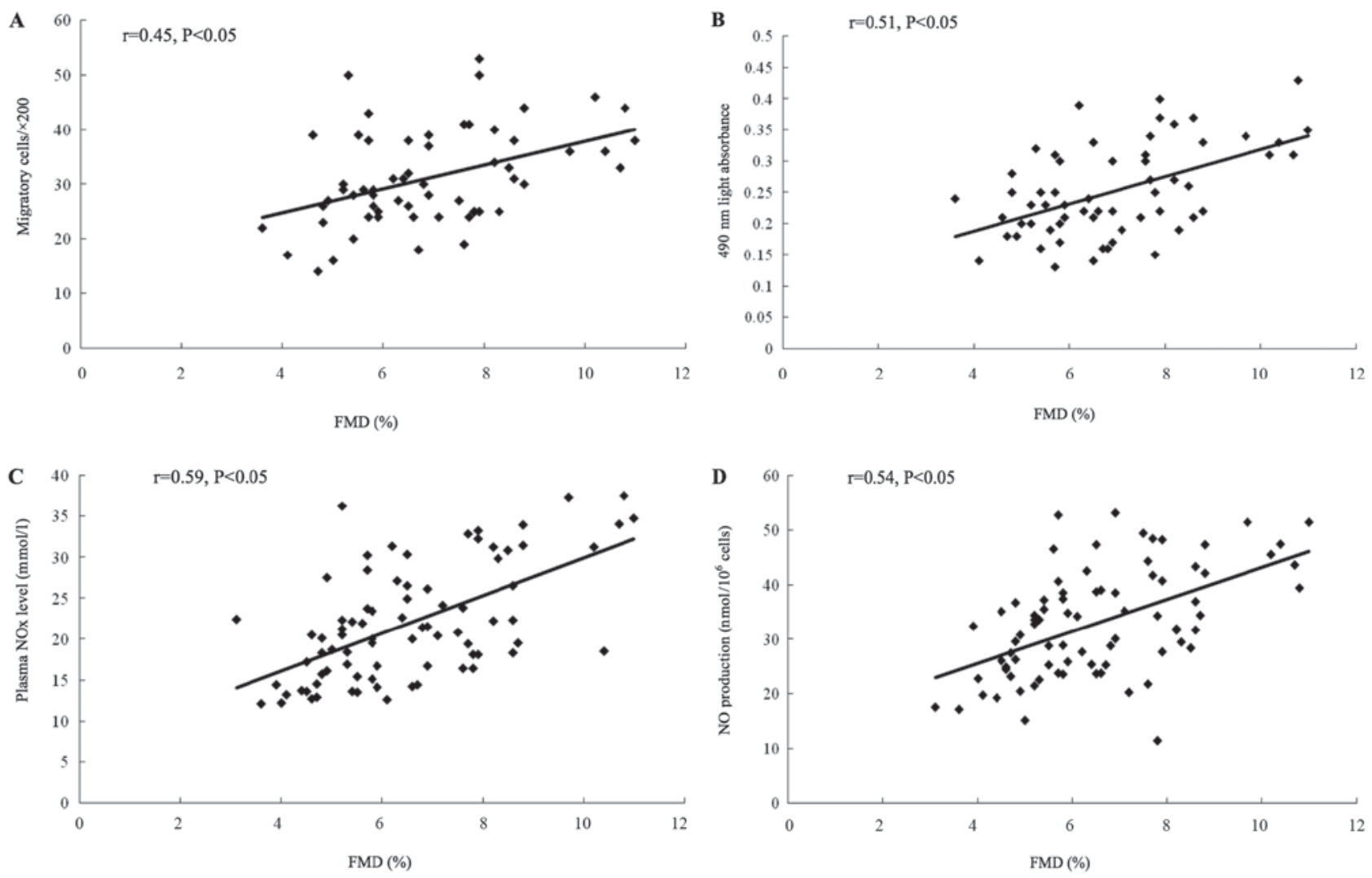

Figure 5. Correlations between the function of circulating EPCs or NO level and FMD. (A) Proliferation and (B) migration of EPCs were markedly correlated with FMD. (C) Plasma NO level, and (D) NO secretion by EPCs were significantly correlated with FMD. EPCs, endothelial progenitor cells; NO, nitric oxide; FMD, flow-mediated dilation.

prehypertensive males and prehypertensive postmenopausal females, which implied that prehypertensive postmenopausal females may have the same cardiovascular risk as age-matched males. Thus, it can be inferred that, as females enter menopause, the EPC function may decrease, which may result in an increase in the cardiovascular risk owing to estradiol decline.

In patients with prehypertension, the migratory and proliferative abilities of circulating EPCs are attenuated, suggesting that EPCs are involved in the pathogenesis of prehypertension through affecting endothelial repair $(11,14)$. It is widely accepted that prehypertensive premenopausal females have more active circulating EPCs in comparison with age-matched males, indicating that sex difference may serve a dominant role in prehypertension-associated endothelial dysfunction at a young age (32-35). Our previous study has demonstrated the improved activity of circulating EPCs in prehypertensive premenopausal females as compared with that in young males, which was associated with higher NO levels in the plasma and NO production by circulating EPCs (20). There is a rational hypothesis is that estradiol may be involved in vascular protection through regulating EPC function. In the present study, attenuated activity of EPCs was observed in prehypertensive postmenopausal females, which appeared to disagree with the findings of our previous study in premenopausal females (20). Furthermore, the alterations in EPC function between prehypertensive and normotensive subjects were detected in males and females. The present results revealed that vascular dysfunction in prehypertensive postmenopausal females may be linked to decreasing EPC-mediated endogenous endothelial repair capacity caused by the decrease in the estradiol-protective effects against CVD.

Numerous studies have indicated that NO, VEGF and GM-CSF can modulate the amount and activity of circulating EPCs (21-24). Endogenous NO biosynthesis has a significant effect on the biological function of EPCs (36). The modulation of NADPH oxidase 2 in human EPCs can restore its physiological function and properties (37). During prehypertension, NO production by early EPCs, which is associated with EPC-mediated endothelial repair capacity $(38,39)$, is markedly decreased (11). In our previous study, it was confirmed that the preserved NO production was associated with elevated circulating EPCs in prehypertensive premenopausal females, rather than VEGF and GM-CSF (20). In the present study, it was further demonstrated that the NO level and NO production in prehypertensive postmenopausal females were similar to those of prehypertensive age-matched males. Furthermore, the VEGF or GM-CSF levels did not differ among the groups, suggesting that the attenuated EPC function in prehypertensive postmenopausal females was independent of alterations in VEGF and GM-CSF levels.

The mechanism of lower NO secretion by EPCs has yet to be defined. However, estrogen may account for the difference in endothelial NO release between males and females (40-42), which may promote NO production via the upregulation of endothelial NO synthase (eNOS) expression, protection against destabilization of eNOS mRNA (43), exertion of antioxidant effects (44), activation of the PI3K/Akt pathway (45), and upregulation of Mas receptor (46). In 
addition, it is presumed that the mechanism may be involved in eNOS expression, which should be discussed in further studies. Apparent discrepancies in EPC function between prehypertensive postmenopausal females and prehypertensive premenopausal females may be due to the pivotal role of estradiol in EPC function protection. Along with the results of previous studies, it can be concluded that the gender difference in EPC function disappears when females enter post-menopause. Furthermore, it is considered that EPC-mediated endothelial repair capacity and endothelium-dependent dilation are impaired in postmenopausal females as a result of the decrease in the estradiol-protective effects against CVD. Thus, the perimenopausal period may be critical for early intervention in prehypertension therapy.

In conclusion, the current study demonstrated that the gender difference in endothelial function and circulating EPCs disappeared in prehypertensive postmenopausal females, which may be associated with the decline in NO production. The attenuated endogenous endothelial repair capacity partly elucidates the decreased endothelial protection in postmenopause. The present findings may provide novel targets for rescuing endothelial dysfunction accompanied by postmenopause and prehypertension.

\section{Acknowledgements}

Not applicable.

\section{Funding}

The study was financially supported by grants from the National Natural Scientific Foundation of China (nos. 81570461).

\section{Availability of data and materials}

The datasets used and/or analyzed during the current study are available from the corresponding author on reasonable request.

\section{Authors' contributions}

CL designed the project. WW, DH, ZW and LL performed the experiments, and collected, analyzed and interpreted the data, as well as generated the figures. WW, LL and ZW wrote the manuscript.

\section{Ethics approval and consent to participate}

The experimental protocol was approved by The Ethical committee of Xiangya Hospital (ethical license ID of human clinical trial, no. 201503377). Written informed consent was provided for participation.

\section{Patient consent for publication}

Not applicable.

\section{Competing interests}

The authors declare that they have no competing interests.

\section{References}

1. Chobanian AV, Bakris GL, Black HR, Cushman WC, Green LA, Izzo JL Jr, Jones DW, Materson BJ, Oparil S, Wright JT Jr, et al: The seventh report of the joint national committee on prevention, detection, evaluation, and treatment of high blood pressure: The JNC 7 report. JAMA 289: 2560-2572, 2003.

2. Xue H, Wang J, Hou J, Li J, Gao J, Chen S, Zhu H and Wu S: Prehypertension and chronic kidney disease in chinese population: Four-year follow-up study. PLoS One 10: e0144438, 2015.

3. Bajpai JK, A P S, A K A, A K D, Garg B and Goel A: Impact of prehypertension on left ventricular structure, function and geometry. J Clin Diagn Res 8: BC07-BC010, 2014.

4. Navarro-Gonzalez JF, Mora C, Muros M, Garcia J, Donate J and Cazana V: Relationship between inflammation and microalbuminuria in prehypertension. J Hum Hypertens 27: 119-125, 2013.

5. Celik T, Yuksel UC, Fici F, Celik M, Yaman H, Kilic S, Iyisoy A, Dell'oro R, Grassi G, Yokusoglu M and Mancia G: Vascular inflammation and aortic stiffness relate to early left ventricular diastolic dysfunction in prehypertension. Blood Press 22: 94-100, 2013.

6. Huang Y, Wang S, Cai X, Mai W, Hu Y, Tang H and Xu D: Prehypertension and incidence of cardiovascular disease: A meta-analysis. BMC Med 11: 177, 2013.

7. Vasan RS, Larson MG, Leip EP, Evans JC, O'Donnell CJ, Kannel WB and Levy D: Impact of high-normal blood pressure on the risk of cardiovascular disease. N Engl J Med 345: 1291-1297, 2001.

8. Vasan RS, Larson MG, Leip EP, Kannel WB and Levy D: Assessment of frequency of progression to hypertension in non-hypertensive participants in the framingham heart study: A cohort study. Lancet 358: 1682-1686, 2001.

9. Schlaich MP, Parnell MM, Ahlers BA, Finch S, Marshall T, Zhang WZ and Kaye DM: Impaired L-arginine transport and endothelial function in hypertensive and genetically predisposed normotensive subjects. Circulation 110: 3680-3686, 2004.

10. Taddei S, Virdis A, Mattei P, Ghiadoni L, Sudano I and Salvetti A: Defective L-arginine-nitric oxide pathway in offspring of essential hypertensive patients. Circulation 94: 1298-1303, 1996.

11. Giannotti G, Doerries C, Mocharla PS, Mueller MF, Bahlmann FH, Horvath T, Jiang H, Sorrentino SA, Steenken N, Manes C, et al: Impaired endothelial repair capacity of early endothelial progenitor cells in prehypertension: Relation to endothelial dysfunction. Hypertension 55: 1389-1397, 2010.

12. Aicher A, Zeiher AM and Dimmeler S: Mobilizing endothelial progenitor cells. Hypertension 45: 321-325, 2005.

13. Hill JM, Zalos G, Halcox JP, Schenke WH, Waclawiw MA, Quyyumi AA and Finkel T: Circulating endothelial progenitor cells, vascular function, and cardiovascular risk. N Engl J Med 348: 593-600, 2003.

14. MacEneaney OJ, DeSouza CA, Weil BR, Kushner EJ, Van Guilder GP, Mestek ML, Greiner JJ and Stauffer BL: Prehypertension and endothelial progenitor cell function. J Hum Hypertens 25: 57-62, 2011.

15. Moreau KL, Hildreth KL, Meditz AL, Deane KD and Kohrt WM: Endothelial function is impaired across the stages of the menopause transition in healthy women. J Clin Endocrinol Metab 97: 4692-4700, 2012.

16. Gavin KM, Seals DR, Silver AE and Moreau KL: Vascular endothelial estrogen receptor alpha is modulated by estrogen status and related to endothelial function and endothelial nitric oxide synthase in healthy women. J Clin Endocrinol Metab 94: 3513-3520, 2009.

17. Denton KM, Hilliard LM and Tare M: Sex-related differences in hypertension: Seek and ye shall find. Hypertension 62: 674-677, 2013.

18. Taddei S, Virdis A, Ghiadoni L, Mattei P, Sudano I, Bernini G, Pinto $\mathrm{S}$ and Salvetti A: Menopause is associated with endothelial dysfunction in women. Hypertension 28: 576-582, 1996.

19. Rudzitis-Auth J, Nenicu A, Nickels RM, Menger MD and Laschke MW: Estrogen stimulates homing of endothelial progenitor cells to endometriotic lesions. Am J Pathol 186: 2129-2142, 2016.

20. Zhen Y, Xiao S, Ren Z, Shen HW, Su H, Tang YB and Zeng H: Increased endothelial progenitor cells and nitric oxide in young prehypertensive women. J Clin Hypertens (Greenwich) 17: 298-305, 2015.

21. Asahara T, Takahashi T, Masuda H, Kalka C, Chen D, Iwaguro H, Inai Y, Silver M and Isner JM: VEGF contributes to postnatal neovascularization by mobilizing bone marrow-derived endothelial progenitor cells. EMBO J 18: 3964-3972, 1999. 
22. Duda DG, Fukumura D and Jain RK: Role of eNOS in neovascularization: NO for endothelial progenitor cells. Trends Mol Med 10: 143-145, 2004.

23. Powell TM, Paul JD, Hill JM, Thompson M, Benjamin M, Rodrigo M, McCoy JP, Read EJ, Khuu HM, Leitman SF, et al: Granulocyte colony-stimulating factor mobilizes functional endothelial progenitor cells in patients with coronary artery disease. Arterioscler Thromb Vasc Biol 25: 296-301, 2005.

24. Yang Z, Wang JM, Chen L, Luo CF, Tang AL and Tao J: Acute exercise-induced nitric oxide production contributes to upregulation of circulating endothelial progenitor cells in healthy subjects. J Hum Hypertens 21: 452-460, 2007.

25. James PA, Oparil S, Carter BL, Cushman WC, Dennison-Himmelfarb C, Handler J, Lackland DT, LeFevre ML, MacKenzie TD, Ogedegbe O, et al: 2014 evidence-based guideline for the management of high blood pressure in adults: Report from the panel members appointed to the Eighth Joint National Committee (JNC 8). JAMA 311: 507-520, 2014.

26. Vasa M, Fichtlscherer S, Aicher A, Adler K, Urbich C, Martin H, Zeiher AM and Dimmeler S: Number and migratory activity of circulating endothelial progenitor cells inversely correlate with risk factors for coronary artery disease. Circ Res 89: E1-E7, 2001

27. Yang Z, Chen L, Su C, Xia WH, Wang Y, Wang JM, Chen F, Zhang YY, Wu F, Xu SY, et al: Impaired endothelial progenitor cell activity is associated with reduced arterial elasticity in patients with essential hypertension. Clin Exp Hypertens 32: 444-452, 2010.

28. Yang Z, Xia WH, Su C, Wu F, Zhang YY, Xu SY, Liu X, Zhang XY, Ou ZJ, Lai GH, et al: Regular exercise-induced increased number and activity of circulating endothelial progenitor cells attenuates age-related decline in arterial elasticity in healthy men. Int J Cardiol 165: 247-254, 2013.

29. Yang Z, Xia WH, Zhang YY, Xu SY, Liu X, Zhang XY, Yu BB, Qiu YX and Tao J: Shear stress-induced activation of Tie2-dependent signaling pathway enhances reendothelialization capacity of early endothelial progenitor cells. J Mol Cell Cardiol 52: 1155-1163, 2012

30. Corretti MC, Anderson TJ, Benjamin EJ, Celermajer D, Charbonneau F, Creager MA, Deanfield J, Drexler H, Gerhard-Herman M, Herrington D, et al: Guidelines for the ultrasound assessment of endothelial-dependent flow-mediated vasodilation of the brachial artery: A report of the international brachial artery reactivity task force. J Am Coll Cardiol 39: 257-265, 2002.

31. Sibal L, Aldibbiat A, Agarwal SC, Mitchell G, Oates C, Razvi S, Weaver JU, Shaw JA and Home PD: Circulating endothelial progenitor cells, endothelial function, carotid intima-media thickness and circulating markers of endothelial dysfunction in people with type 1 diabetes without macrovascular disease or microalbuminuria. Diabetologia 52: 1464-1473, 2009.

32. Lemieux C, Cloutier I and Tanguay JF: Menstrual cycle influences endothelial progenitor cell regulation: A link to gender differences in vascular protection? Int J Cardiol 136: 200-210, 2009.

33. Hoetzer GL, MacEneaney OJ, Irmiger HM, Keith R, Van Guilder GP, Stauffer BL and DeSouza CA: Gender differences in circulating endothelial progenitor cell colony-forming capacity and migratory activity in middle-aged adults. Am J Cardiol 99: 46-48, 2007.
34. Rousseau A, Ayoubi F, Deveaux C, Charbit B, Delmau C, Christin-Maitre S, Jaillon P, Uzan G and Simon T: Impact of age and gender interaction on circulating endothelial progenitor cells in healthy subjects. Fertil Steril 93: 843-846, 2010.

35. Fadini GP, de Kreutzenberg S, Albiero M, Coracina A, Pagnin E, Baesso I, Cignarella A, Bolego C, Plebani M, Nardelli GB, et al: Gender differences in endothelial progenitor cells and cardiovascular risk profile: The role of female estrogens. Arterioscler Thromb Vasc Biol 28: 997-1004, 2008.

36. Aicher A, Heeschen C and Dimmeler S: The role of NOS3 in stem cell mobilization. Trends Mol Med 10: 421-425, 2004.

37. De Falco E, Carnevale R, Pagano F, Chimenti I, Fianchini L, Bordin A, Siciliano C, Monticolo R, Equitani F, Carrizzo A, et al: Role of NOX2 in mediating doxorubicin-induced senescence in human endothelial progenitor cells. Mech Ageing Dev 159: 37-43, 2016.

38. Aicher A, Heeschen C, Mildner-Rihm C, Urbich C, Ihling C, Technau-Ihling K, Zeiher AM and Dimmeler S: Essential role of endothelial nitric oxide synthase for mobilization of stem and progenitor cells. Nat Med 9: 1370-1376, 2003

39. Sorrentino SA, Bahlmann FH, Besler C, Muller M, Schulz S, Kirchhoff N, Doerries C, Horvath T, Limbourg A, Limbourg F, et al: Oxidant stress impairs in vivo reendothelialization capacity of endothelial progenitor cells from patients with type 2 diabetes mellitus: Restoration by the peroxisome proliferator-activated receptor-gamma agonist rosiglitazone. Circulation 116: 163-173, 2007.

40. Darkow DJ, Lu L and White RE: Estrogen relaxation of coronary artery smooth muscle is mediated by nitric oxide and cGMP. Am J Physiol 272: H2765-H2773, 1997.

41. Thompson $\mathrm{J}$ and Khalil RA: Gender differences in the regulation of vascular tone. Clin Exp Pharmacol Physiol 30: 1-15, 2003.

42. Iwakura A, Luedemann C, Shastry S, Hanley A, Kearney M, Aikawa R, Isner JM, Asahara $T$ and Losordo DW: Estrogen-mediated, endothelial nitric oxide synthase-dependent mobilization of bone marrow-derived endothelial progenitor cells contributes to reendothelialization after arterial injury. Circulation 108: 3115-3121, 2003.

43. Sumi D, Hayashi T, Jayachandran M and Iguchi A: Estrogen prevents destabilization of endothelial nitric oxide synthase mRNA induced by tumor necrosis factor alpha through estrogen receptor mediated system. Life Sci 69: 1651-1660, 2001.

44. Wagner AH, Schroeter MR and Hecker M: 17beta-estradiol inhibition of NADPH oxidase expression in human endothelial cells. FASEB J 15: 2121-2130, 2001.

45. Hohmann N, Xia N, Steinkamp-Fenske K, Forstermann U and $\mathrm{Li} \mathrm{H}$ : Estrogen receptor signaling and the PI3K/Akt pathway are involved in betulinic acid-induced eNOS activation. Molecules 21: E973, 2016.

46. Sobrino A, Vallejo S, Novella S, Lázaro-Franco M, Mompeón A, Bueno-Betí C, Walther T, Sánchez-Ferrer C, Peiró $\mathrm{C}$ and Hermenegildo C: Mas receptor is involved in the estrogen-receptor induced nitric oxide-dependent vasorelaxation. Biochem Pharmacol 129: 67-72, 2017. 